\title{
Loss of TP53-DNA interaction induced by p.C135R in lung cancer
}

\author{
MARCELA ARANDA ${ }^{1}$, FERNANDO GONZALEZ-NILO ${ }^{2}$, GONZALO RIADI ${ }^{2}$, VICTOR DÍAZ ${ }^{1}$, \\ JOSÉ PEREZ ${ }^{1}$, GHYSLAINE MARTEL ${ }^{3}$, PIERRE HAINAUT ${ }^{3}$ and ADRIANA MIMBACAS ${ }^{4}$ \\ ${ }^{1}$ Department of Biology, Facultad de Química y Biología, Universidad de Santiago de Chile; ${ }^{2}$ Centro de Bioinformática y \\ Simulación Molecular, Universidad de Talca, Chile; ${ }^{3}$ International Agency for Research on Cancer, Lyon, France; \\ ${ }^{4}$ División Citogenética, Unidad Asociada, Instituto de Biología, Facultad de Ciencias, Montevideo, \\ Uruguay e Instituto de Investigaciones Biológicas Clemente Estable, Montevideo, Uruguay
}

Received July 6, 2007; Accepted August 29, 2007

\begin{abstract}
The p53 tumor suppressor gene (TP53; OMIM: 191170) plays an important role in tumorigenesis in lung epithelial cells. TP53 encodes a sequence-specific DNAbinding protein that regulates transcription of several genes in response to DNA damage promoting cell cycle arrest, DNA repair or apoptosis. A mutation does not necessarily alter the protein function and since not all altered tumor protein p53 (TP53) conformations lead to the same biological properties, we studied Cys135Arg TP53 gene mutation in squamous cell type of non-small cell lung cancers (NSCLCs), by polymerase chain reaction-single-strand conformation polymorphism (PCR-SSCP) and direct sequencing. Cys 135Arg TP53 mutation, rare in databases $(11 / 23544$ in R11, IARC TP53 database), was detected. We chose p.C135R in order to examine DNA-TP53 interaction. A comparison with the wild-type after 1 nano-second molecular dynamic simulation analysis revealed a significant structural change (over $4 \AA$ displacement) in the contact loop Lys-Ser-Val which lies upstream and next to the mutated site in the TP53, that sterically prevents its DNA-binding activity. Additionally, the mutation produced a change in the electrostatic potential surface of the protein in the same loop where the structural modification took place. To demonstrate the degree of loss of function, functional assays in yeast and bacteria with oligonucleotides for competitive electrophoretic mobility shift assays (EMSAs) were done proving that this mutation decreases TP53 ability to bind DNA of the TP53 response element from the human $p 21$ gene. These results demonstrate
\end{abstract}

Correspondence to: Dr Marcela Aranda, Casilla 40, Correo 33, Santiago de Chile, Chile

E-mail: maranda@lauca.usach.cl

Key words: non-small cell lung carcinoma, TP53, tumor suppressor gene, polymerase chain reaction-single-strand conformation polymorphism, sequencing, molecular dynamics, simulation, sterical effect, modeling, EMSA, protein/DNA, mutations that the amino acid change C135R in the human TP53 generates the loss of TP53 DNA-binding activity directly affecting its role as a transcription factor and suggests that this observation can explain part of the phenotype described in patients affected by this type of tumor.

\section{Introduction}

Somatic TP53 mutations have been described in almost all types of cancers with a variable prevalence depending on the type of cancer. In cancers of the upper aero-digestive tract (oral, esophageal or bronchial cancers), TP53 is mutated in up to $75 \%$ of the cases of invasive cancers and particularly in smokers who are exposed to mutagens, it is often detectable in early, pre-neoplastic lesions $(1,2)$ and according to smoking status (3).

The tumor-derived missense mutations may inactivate TP53 by affecting its ability to bind to DNA. Accordingly, a number of tumor-derived missense mutations were shown to be functionally defective and differ by their degree of loss of function. Functional assays in yeast, zebrafish and human cells have shown that some mutant proteins retain residual transcriptional activity for a subset of target genes (4). Indeed, the wild-type TP53 protein does not bind equally to the different TP53-targeted promoters. For example, the $p 21$ promoter appears to contain binding sites of higher affinity than the $B A X$ promoter (5). Some mutants, as for example, arginine to proline at codon $175(\mathrm{R} 175 \mathrm{P})$ and arginine to cysteine at codon 181 (R181C), retain the capacity to transactivate $p 21$ but are defective for $B A X$ activation and fail to induce apoptosis $(6,7)$. It was shown that a majority of mutants affected in the DNA-binding domain have an impaired transcriptional activity, whereas most of the mutants affected in other regions retain, at least partially, transcriptional activity on various p53-responsive promoters (8). Lung cancer tumors of non-small cell lung cancer (NSCLC) have an incidence between $75-95 \%$ in relation to small cell lung cancer (SCLC). Squamous cell carcinoma, adenocarcinoma and large cell carcinoma are three types of NSCLC (9). In Chile, mortality rates were $27.15 / 100.000$ for men and 8.45 for women (2). 
In this study, we carried out an investigation of the structure and functional activities of a possible new spot mutant in squamous cell carcinoma in Latin America.

\section{Materials and methods}

Study subjects. Patients with non-small cell lung cancer were recruited at the hospitals responsible for diagnosis and treatment of lung cancer. The study was approved by the Ethics Committee, informed consent was obtained and detailed exposure data were collected, usually after the time of bronchoscope biopsies or surgically resected tumor specimen's collection. Of the 35 patients with squamous cell carcinoma analyzed in the present study, $75 \%$ were men.

TP53 mutation analysis. Tumor and normal genomic DNA was extracted as previously described (10) from tumor and adjacent normal tissue samples of the same patient. The DNA was screened for mutations in the DNA-binding domain 'mutation hotspots' (exons 5-9), using polymerase chain reaction and single-strand conformation polymorphism (PCR-SSCP) (11). Reactions with B-actin or GAPDH genes and reactions without DNA were used as an internal control in PCR amplifications. All mutations were confirmed by complete repeats of the experimental procedure. The amplified fragments were analyzed by $1.5 \%$ agarose gel electrophoresis in TAE buffer. Cold single-strand conformational polymorphism (SSCP) was performed in a $15 \%$ non-denaturating polyacrylamide gels $(11)$ at $4^{\circ} \mathrm{C}, 100 \mathrm{~V}$ for $8 \mathrm{~h}$ in a mini-V 8-10 (Gibco). The criterion used for a positive finding in SSCP was that the same band pattern had to be detected in at least two independent PCR products from the original tumor DNA.

Exons showing aberrant band shifts on SSCP were reamplified and the PCR products were directly sequenced. PCR-SSCP analysis and DNA sequencing were performed in parallel on the tumor and normal lung tissue samples. One mutated sample was confirmed by denaturing highperformance liquid chromatography (DHPLC) at the International Agency for Research on Cancer, Lyon, France (IARC). Databases were revised to determine the frequency of the mutation in this type of carcinoma (http://www. p53.iarc.fr).

Molecular dynamics methodology. Atomic coordinates of TP53 were taken from the crystallographic structures at the Brookhaven Protein Data Bank (PDB): PDB code, 1TUP (12); resolution $(2.20 \AA)$. To simplify the analysis, the DNA and the monomer unit $\mathrm{A}$ and $\mathrm{C}$ were deleted from the TP53 pdb file. The structure of monomer B was taken as reference to build a model for wild-type TP53 and p.C135R. These models represented the TP53 in a free state, without interaction with the DNA, so we could study the structural perturbation caused only by the mutation C135R. To analyse the wild-type and the mutant TP53, both proteins were submitted to the same Molecular Dynamics protocols. The models were built and relaxed for $1 \mathrm{~ns}$ using the force field CHARMm 27 (13). All hydrating water molecules within $3 \AA$ from the protein were preserved. Protein hydrogens were added by using the HBUILD module of CHARMm. The tautomeric states of histidines were assigned according to the local environment in the models. His 179, Cys 176, 238 and 242 were protonated to improve the coordination of $\mathrm{S}$ atom with the $\mathrm{Zn}^{+2}$ cation.

Electrostatic potential and electrostatic solvation properties between TP53 and DNA were calculated using DelPhi software (14) with the following parameters: solute dielectric constant (2.0), solute extent (50.00), solvent dielectric constant (90), solvent radius (1.4), solvent ionic strength (1.45), solvent ionic radius (2.00) and number of grid points (81). Electrostatic potential grids generated by DelPhi were viewed as contour maps using MSI's 3D graphical interface, Insight II (Insight II Reference Guide). By viewing 3D potential contours, DelPhi enabled the evaluation of shape and extent of electrostatic potential inside and around the wildtype and p.C135R. The solvent accessible surface or Connolly surface and the root mean square distance (RMSD) were used for figures.

Cloning TP53 PCR product. pBAD/TP53 plasmid was generated to clone, express and purify the human TP53 protein in E. coli. Plasmid pBAD/TP53 was constructed by insertion of the TP53 PCR amplified gene product into the expression vector pBADTOPO (Invitrogen). Briefly, the TP53 gene was amplified using chromosomal DNA as a template. The PCR product was ligated to pBAD-TOPO and cloned into E. coli. Top10 as recommended by the vendor. PCR insert orientation was confirmed by NcoI endonuclease digestion and TP53 protein expression was confirmed by Western blot (15).

To express the TP53 gene in $S$. cereviseae, the plasmid pYES2/CT/TP53 was constructed. The amplified TP53 gene was ligated to pGEMTeasy and cloned in E. coli DH5 $\alpha$ using the protocol suggested by the vendor (Invitrogen). The primers used for the PCR amplification were: 5' gcgaagcttgc cctcaacaagatgtttcgccaa 3' (mutant) and 5' gcgaagcttgccetcaac aagatgttttgccaa $3^{\prime}$ (wild-type) and the reverse primer 5' cccag gatcccagttgcaaaccagacctcag 3'. Recombinant plasmids were extracted and digested with HindIII-BamHI endonucleases for $3 \mathrm{~h}$ at $37^{\circ} \mathrm{C}$. Bands were extracted from the gel using a miniprep plasmid extraction kit (Qiagen). The band corresponding to TP53 gene digested with HindIII-BamHI were ligated to a pYES2/CT plasmid previously digested with HindIII-BamHI. Ligation mix was used to electroporate the yeast PUK-3B ade-ura- (400 volts, $10 \mu \mathrm{F}$ and low resistant; Biorad MicroPulser ${ }^{\mathrm{TM}}$ electroporation apparatus). The presence of colonies was evident after 5 days of incubation. For PCR amplification of transformed $S$. cereviseae, primers containing restriction sites of HindIII (forward) and BamHI (reverse) were used.

Cellular growth conditions and protein overexpression. E. coli cells transformed with $\mathrm{pBAD} / \mathrm{TP} 53$ were grown in LB media at $37^{\circ} \mathrm{C}$ until an $\mathrm{OD}_{600} \approx 0.6$ was reached. At this point, the expression of recombinant proteins was induced adding Larabinose $(0.2 \%)$ and incubating the cells for a period of $4 \mathrm{~h}$. The cells were then obtained by centrifugation $(13,000 \mathrm{rpm} \mathrm{x}$ $10 \mathrm{~min}$ ) re-suspended in Tris- $\mathrm{HCl} 50 \mathrm{mM}(\mathrm{pH} 7.0)$ buffer and lysed by sonic disruption. Streptomycin sulphate (2\%) for nucleic acids precipitation and protease inhibitor (PMSF) were added to the supernatant obtained after centrifugation of the lysates. After centrifugation (13,000 rpm x $10 \mathrm{~min})$ the 

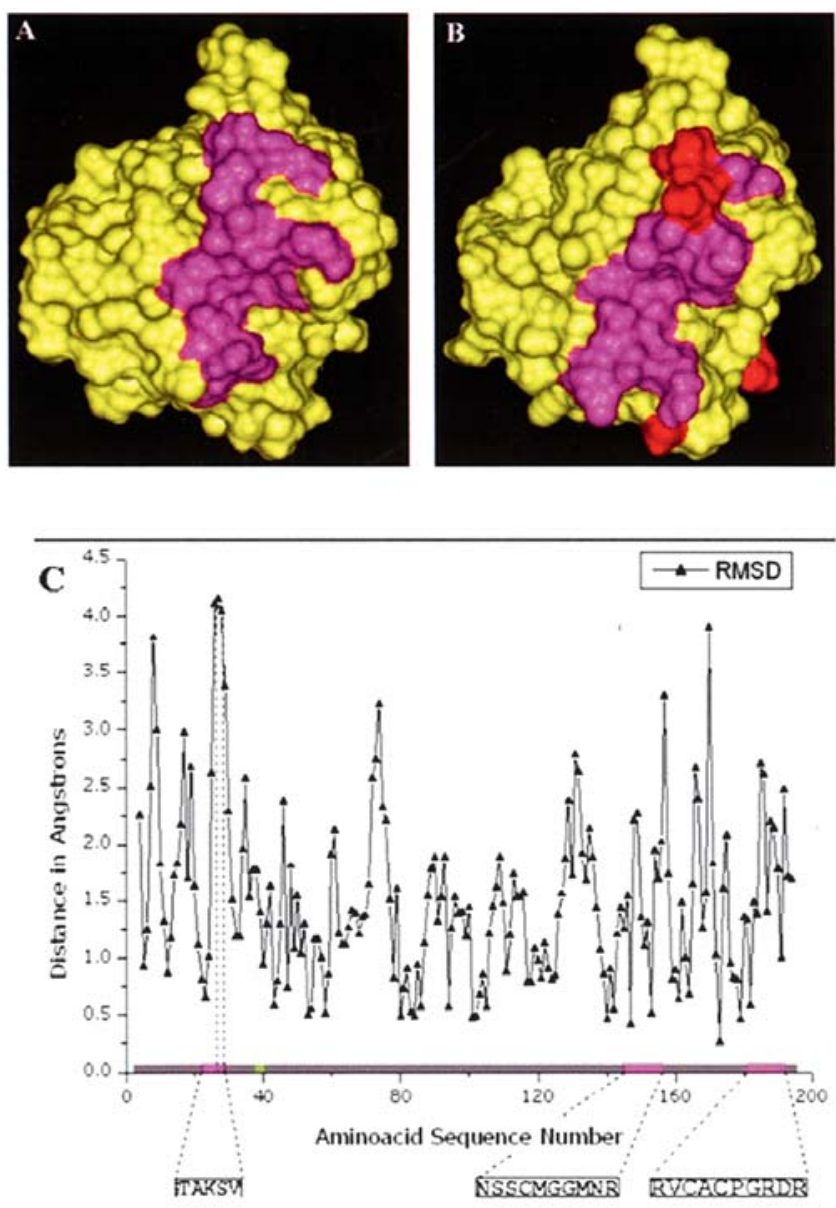

Figure 1. Comparison of Connolly surface of relaxed TP53 wild-type (A) and p.C135R (B). Electrostatic potential surface on the relaxed mutant TP53 seen in the same position. The chart (C) shows the RMSD between (A) and (B) along the amino acid sequence. In purple, the pictures and the chart show the contact surface with the DNA. In the mutant, the purple corresponds to the amino acids that contact the DNA. In red, the largest differences according to the chart are due to the C135R mutation. The green point in the abscission axis represents the mutation position. As the mutation is placed in an internal point of the structure, this is not shown.

supernatant was obtained (crude extracts) and used for protein purification.
$S$. cereviseae cells were grown in YPD medium amended with galactose at $37^{\circ} \mathrm{C}$ during $4 \mathrm{~h}$. Protein extracts were obtained using a spheroplast preparation according to the supplier's instructions.

Purification of proteins was performed using the Ni-NTA purification system that allows purification of proteins that contain a 6xHis tag (Invitrogen). Protein crude extracts were charged in a $\mathrm{Ni}^{+2}$ column (Ni-TA) and imidazol was used to elute the protein as recommended by the manufacturer. To detect the mutant or wild-type proteins, a specific antibody designed to recognize the $6 \mathrm{xHis}$ epitope was used. Protein identity and purity was evaluated by Western blot and SDSPAGE respectively.

Probes. The sequence of oligonucleotides used in the EMSA experiments corresponding to the TP53 response element from the human $p 21$ gene (REp21) were: 5'-CAAGCTGGTTGAA CATGTCCCAACATGTTGGGCGGGAAGC-3'; 5'-GCT TCCCGCCCAACATGTTGGGACATGTTCAACCAGC TTG-3. The boldface nucleotides in the sequence indicate the TP53 binding sites determined (16).

DNA binding assays. The purified p53 wt and p.C135R proteins were used to compare their affinities for p53 DNA binding motifs present in the TP53 response element from the human $p 21$ gene (REp21). ${ }^{32} \mathrm{P}$-marked REp21 probe (200 $\mathrm{ng} / \mu \mathrm{l}$ ) was incubated with the protein at a final concentration of $10 \mathrm{ng} / \mu \mathrm{l}$. Then the reaction products were charged on a non-denaturing polyacrylamide gel and the competitive EMSA assays were developed by autoradiography. Nucleotides were marked with $\gamma$ ATP-P32 ( 32000 $\mathrm{cpm} / \mu \mathrm{l}$ ) with T4 PNK (Fermenta).

\section{Results}

Mutations in TP53. During the study of 35 tumors, 4 were found with a new mutation in the central domain of $\mathrm{p} 53$, p.C135R. Additionally, known mutations involving amino acids in the DNA-binding domain in the same or other types of cancer, were identified (17).

Molecular simulations. Using molecular simulation tools, we obtained the root mean square distance (RMSD) versus the

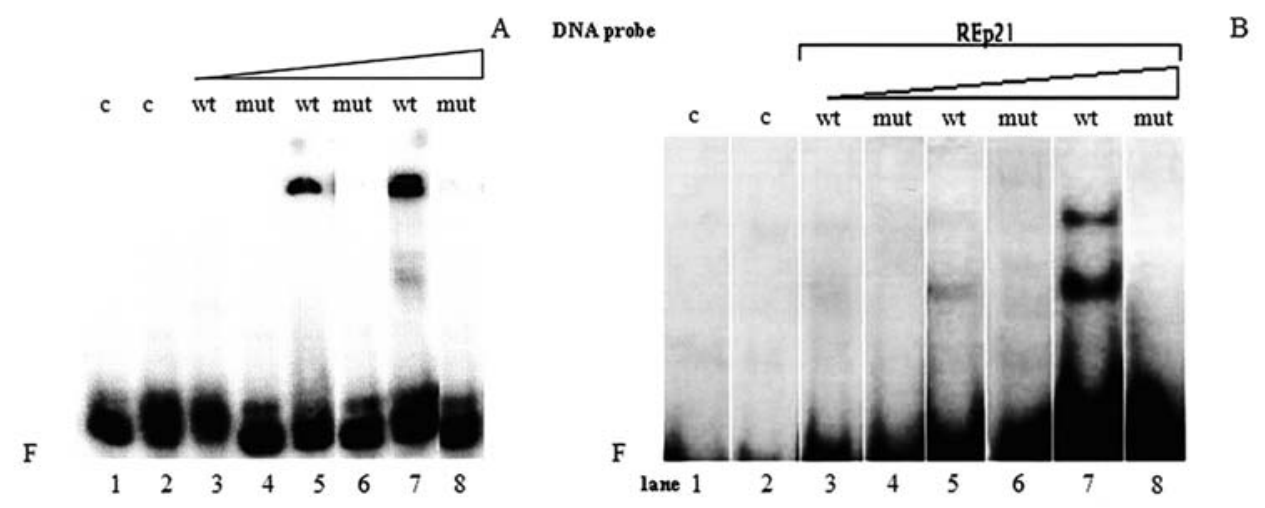

Figure 2. TP53 - Rep21 DNA interaction. Purified TP53 expressed by E. coli cells (A) and yeast PUK-3B ade-ura (B) were incubated with ${ }^{32}$ P-labeled DNA probes and resolved by EMSA. Lane 1: control, negative probe + wt TP53. Lane 2: control, Rep21. Lanes 3 and 4: 50 ng protein. Lanes 5 and 6: 100 ng protein. Lanes 7 and 8: $150 \mathrm{ng}$ protein. Rep21 is the TP53 response element from the human $p 21$ gene. F, the position of the free DNA probe. 
amino acid sequence (Fig. 1). The graphic representation of the interface TP53-DNA and the region with structural perturbation for the mutation $\mathrm{C} 135 \mathrm{R}$ is shown. Clearly, the greatest structural change occurred in the first of the contact zones, involving at least three aminoacids (K-S-V). Fig. 1 shows the conformational alterations at the same position of the Conolly surface of wild-type and mutant proteins after structure energy minimization analysis. The changes in the electrostatic potential pattern in mutant versus wild-type TP53 protein, including the DNA contact zones where significant structural changes occurred, took place due to the mutation. TP53 wt electrostatic potential changes significantly when bound to DNA. From the structural analysis, we predicted that p.C135R had an impaired capacity to bind to DNA. In order to verify this experimentally, we used oligonucleotides for competitive electrophoretic mobility shift assays.

Determination of protein-DNA interactions. By EMSA we showed an inhibited DNA-binding capacity of p.C135R to a TP53 response element from the human $p 21$ gene, nevertheless the wild-type protein was able to bind to the sequence and remained as a strong band in the gel (Fig. 2). Even at higher concentrations such as $150 \mathrm{ng}$ of the mutant protein, the binding capacity to the TP53 response element from the human $p 21$ gene was inhibited (Fig. 2).

\section{Discussion}

Mutant codon 135, TGC/CGC, was reported as a somatic mutation in 11/23544 tumors (R11, IARC TP53 database) non-functional in yeast (17). For all reported experimental results, this mutant lost its capacity to transactivate the TP53 target genes. This mutation in the central domain of TP53 was not reported in NSCLC, but was reported once in SCLC in Germany (17). Mathe et al established that substitutions at positions that are highly conserved are strongly selected for during tumorigenesis, in areas that contain the mutation hotspots (residues 171-181, 237-258 and 270-282) of TP53 (18). The new mutation in the central domain of TP53, $\mathrm{pC} 135 \mathrm{R}$, rare in this type of tumor, induces a change in the structure of TP53 transcription factor that prevents its DNA binding capacity. The molecular simulation suggests that this amino acid change generates an important structural perturbation that can modify the binding affinity of the protein to the target DNA (over $4 \AA$ displacement). Specifically, the mutation Cys135Arg produces modifications on the topology of the TP53 epitopes that, in the wild-type, eventually interact with the DNA. The chart (Fig. 1) shows the RMSD between wild-type and mutant along the amino acid sequence. In the mutant, we can see the largest differences are due to the C135R mutation. Clearly, a significant change can be seen in the electrostatic potential pattern, including the DNA contact zones and other zones where significant structural change occurred due to the mutation. This pattern change negatively affects the process of union with the nucleic acid. Furthermore, this change can be a second factor preventing the union with DNA, together with geometrical surface changes caused by the mutation.

As the mutation is placed in an internal point of the structure, this suggests that $135 \mathrm{Cys}$ is essential in maintaining the protein structure.
Based on the predictions obtained from the molecular simulation results, we examined the effect of the Cys135Arg in the affinity of this protein to DNA (Fig. 2). We demonstrated that the TP53 mutant protein present in squamous cell carcinoma is importantly affected the DNA-binding capacity to the human $p 21$ gene (a p53 response element). On activation, TP53 binds to an array of gene promoters, such as $p 21$, some of which are responsible for stress-induced cell cycle arrest, whereas others, such as bax and puma, are responsible for driving cells into apoptosis. Recently it was suggested that p21-activated kinase 1 (PAK1) through its kinase inhibitory domain (KID) and induced a cell cycle arrest with the accumulation of cells in the G1 phase of the cell cycle producing an inhibition of cyclin D1 and D2 expression $(19,20)$. The activation of the TP53/p21 pathway by a DNAdamaging agent up-regulates $\mathrm{p} 27$ and promulgates TP53/p21/ p27 axis as a significant component of checkpoint response (21).

This situation directly affects the role as a transcription factor and suggests that p.C135R cannot induce cell cycle arrest by inhibition via TP53/p21 response and the genes regulated by this protein are not regulated in cells expressing the TP53 mutant protein. This observation can explain part of the phenotype described in patients affected by this kind of tumor. These findings warrant further testing in a larger series of patients to determine a hotspot with a particular epidemiology.

\section{Acknowledgements}

We are grateful to Dr Magali Olivier for her assistance and valuable opinion. Supported by a grant from DICYT-USACH (08-0595AL).

\section{References}

1. Pisani P, Bray F and Parkin DM: Estimates of the world-wide prevalence of cancer for 25 sites in the adult population. Int $\mathbf{J}$ Cancer 97: 72-81, 2002.

2. Bosetti C, Malvezzi M, Chatenoud L, Negri E, Levi F, La Vecchia C: Trends in cancer mortality in the Americas 1970-2000. Ann Oncol 16: 489-511, 2005.

3. Le Calvez F, Mukeria A, Hunt JD, Kelin O, Hung RJ, Taniere P, Brennan P, Boffetta P, Zaridze DG and Hainaut P: TP53 and KRAS mutation load and types in lung cancers in relation to tobacco smoke: distinct patterns in never, former and current smokers. Cancer Res 65: 5076-5083, 2005.

4. Berghmans S, Murphey RD, Wienholds E, Neuberg D, Kutok JL, Fletcher CD, Morris JP, Liu TX, Schulte-Merker S, Kanki JP, Plasterk R, Zon LI and Look AT: TP53 mutant zebrafish develop malignant peripheral nerve sheath tumors. Proc Natl Acad Sci USA 102: 407-412, 2005.

5. Flaman JM, Robert V, Lenglet S, Moreau V, Iggo R and Frebourg T: Identification of human p53 mutations with differential effects on the BAX and p21 promoters using functional assays in yeast. Oncogene 16: 1369-1372, 1998.

6. Ludwig RL, Bates S and Vousden KH: Differential activation of target cellular promoters by p53 mutants with impaired apoptotic function. Mol Cell Biol 16: 4952-4960, 1996.

7. Smith PD, Crossland S, Parker G et al: Novel p53 mutants selected in BRCA-associated tumours which dissociate transformation suppression from other wild-type p53 functions. Oncogene 18: 2451-2459, 1999.

8. Kato S, Han SY, Liu W, et al: Understanding the functionstructure and function-mutation relationships of p53 tumor suppressor protein by high-resolution missense mutation analysis. Proc Natl Acad Sci USA 100: 8424-8429, 2003.

9. Mitsudomi T, Hamajima N, Ogawa M et al: Prognostic significance of P53 alterations in patients with non-small cell lung cancer: a meta-analysis. Clin Cancer Res 6: 4055-4063, 2000. 
10. Sambrook J, Fritsch EF and Maniatis T: Molecular Cloning. In: A laboratory manual. (2nd ed) Cold Spring Harbor Laboratory, Cold Spring Harbor, NY, 1989.

11. Hongyo T, Buzard G, Calvert R and Weghorst C: 'Cold SSCP': a simple, rapid and non-radioactive method for optimized singlestrand conformation polymorphism analysis. Nucleic Acids Res 21: 3637-3642, 1993.

12. Cho YJ, Gorina S, Jeffrey PD and Pavlatich NP: Crystal structure of a p53 tumor suppressor-DNA complex: understanding tumorigenic mutations. Science 265: 346-355, 1994.

13. Brooks BR, Bruccoleri RE, Olafson BD, States DJ, Swaminathan S and Karplus M: Charmm: A Program for macromolecular energy, minimization, and dynamics calculations. J Comp Chem 4: 187-217, 1983.

14. Friedman RA and Honig B: A free energy analysis of nucleic acid base stacking in aqueous solution. Biophys J 69: 1528-1535, 1995.

15. Sambrook J, Russell WD and Sambrook J: Molecular Cloning. Cold Spring Harbor Laboratory Press, 2000.

16. Tan $\mathrm{T}$ and Chu G: $\mathrm{p} 53$ binds and activates the Xeroderma Pigmentosum $D D B 2$ gene in humans but not mice. Mol Cell Biol 22: 3247-3254, 2002.
17. Olivier M, Eeles R, Hollstein M, Khan MA, Harris CC and Hainaut P: The IARC TP53 Database: new online mutation analysis and recommendations to users. Hum Mutat 19: 607-614, 2002 .

18. Mathe E, Olivier M, Kato S, Ishioka C, Hainaut P and Tavtigian SV: Computational approaches for predicting the biological effect of p53 missense mutations: a comparison of three sequence analysis based methods. Nucleic Acids Res 34: $1317-1325,2006$.

19. He G, Siddik ZH, Huang Z, Wang R, Koomen J, Kobayashi R, Khokhar AR and Kuang J: Induction of p21 by p53 following DNA damage inhibits both Cdk4 and Cdk2 activities. Oncogene 21: 2929-2943, 2005.

20. Thullberg M, Gad A, Beeser A, Chernoff J and Stromblad S: The kinase-inhibitory domain of p21-activated kinase 1 (PAK1) inhibits cell cycle progression independent of PAK1 kinase activity. Oncogene 26: 1820-1828, 2007.

21. He G, Kuang J, Huang Z, Koomen J, Kobayashi R, Khokhar AR and Siddik ZH: Upregulation of p27 and its inhibition of CDK2/cyclin E activity following DNA damage by a novel platinum agent are dependent on the expression of $\mathrm{p} 21$. Br J Cancer 95: 1514-1524, 2006. 